\title{
Dr. Li Wenliang and the Time of COVID-19
}

\author{
Johannes Czernin \\ David Geffen School of Medicine at UCLA, Los Angeles, California
}

$\mathbf{T}$ hese are difficult times for all of us. None of us has ever experienced anything like the current pandemic. Nuclear medicine clinics are usually very safe, low-risk, low-stress environments. This has changed now as each patient can be infected, and staff members can be asymptomatic carriers or become symptomatic while providing services. Although mortality rates are low, the huge number of infections poses enormous challenges for healthcare systems worldwide. Medical personnel are stretched to the limits. While this editorial was being written, one of our staff members tested positive for COVID-19. How do you protect patients and staff without discontinuing essential clinical services? A specific example is provided by Dr. Zuckier et al. (1), who propose elimination of the ventilation portion from lung perfusion/ ventilation scans, as aerosols can be an infection source.

A more general assessment was spearheaded by Dr. Ken Herrmann, who asked global leaders to provide their safety strategies (2). We apologize for not including comments from many other institutions. Time was too short to reach out to many more of you. We will consider Letters to the Editor specifying additional measures that can help provide safer environments.

We thank the hundreds of thousands of health-care workers worldwide who have not hesitated for a moment to come in and do their job at times of great personal risk. I am certain that you all share our experience at UCLA: these are selfless people who help and support each other; cover for each other; and volunteer to step in and up as needed.

Dr. Li Wenliang was reprimanded initially for "disrupting public order" in China when he first reported the outbreak in Wuhan. He died, and the Chinese government has finally sent a "solemn apology" to him. There are many

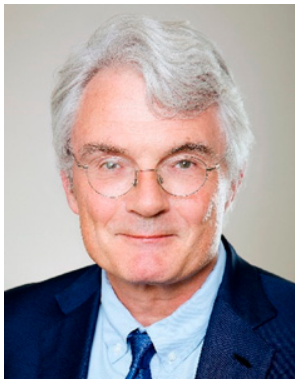

Johannes Czernin more physicians, technologists, nurses, and administrators who fell severely ill or died.

These are our heroes.

\section{REFERENCES}

1. Zuckier LS, Moadel RM, Haramati LB, Freeman LM. Diagnostic evaluation of pulmonary embolism during the COVID-19 pandemic. J Nucl Med. 2020;61: 630-631.

2. Czernin J, Fanti S, Meyer PT, et al. Imaging clinic operations in the times of COVID-19: strategies, precautions, and experiences. J Nucl Med. 2020;61:626629 . 